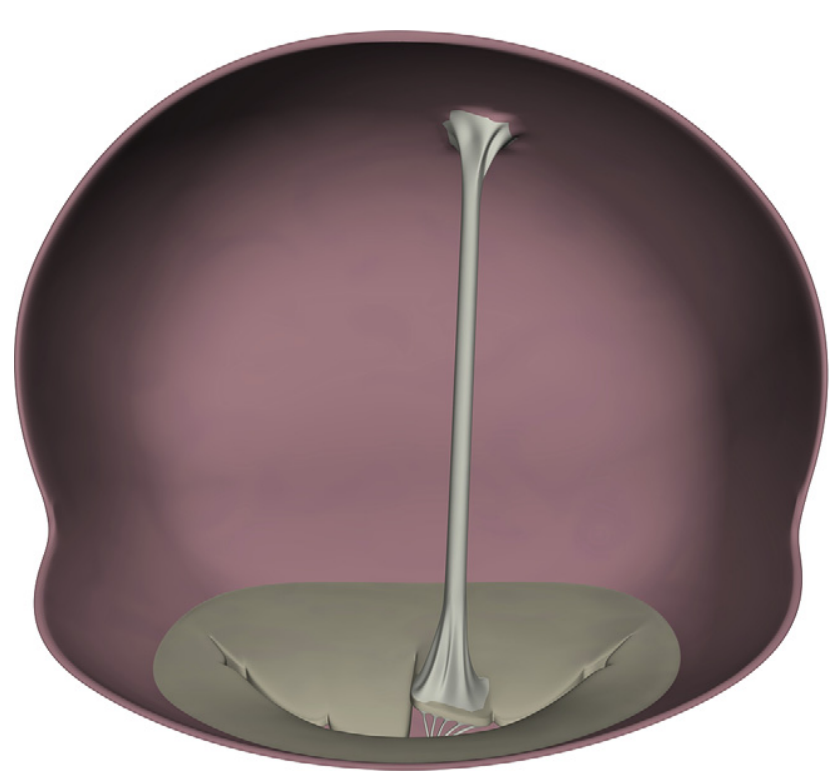

FIGURE 3. Three-Dimensional computer-generated rendering depicting the attachment of the abnormal chordae between the dome of the left atrium and the anterior leaflet of the mitral valve.

best of our knowledge, there are only 3 other reports of an accessory chordae tendinae located in the left atrium, ${ }^{10-12}$ with one report describing a prolapsing chordae through the mitral aperture $^{11}$ and a fibrous band tethering the anterior mitral leaflet to the edge of the fossa ovalis. ${ }^{12}$ We present an unusual case of an accessory left atrial chordae tendinae associated with a partial cleft of the anterior mitral leaflet.
We thank Michelle J. Marge, RN, and Patricia M. Stevens, RDCS, of Christiana Hospital Center for Heart and Vascular Health for their invaluable assistance with image acquisition and processing.

\section{References}

1. Gillinov M, Banbury MK. Pre-measured artificial chordae for mitral valve repair. Ann Thorac Surg. 2007;84:2127-9.

2. Kuboki K, Ohkawa S, Maeda S, Chida K, Imai T, Kataoka S, et al. Clinicopathologic study of mitral regurgitation due to abnormal chordae tendinae. J Cardiol. 1996;27:187-95.

3. Yamamoto Y, Shimada R, Kaseda S, Tomoike H, Takeshita A, Nakamura M. Two-dimensional echocardiographic documentation of accessory chordae tendinae accompanying isolated anterior mitral cleft. Am Heart J. 1984;108:1554-6.

4. De Segni E, Kaplinsky E, Klein HO. Color Doppler echocardiography of isolated cleft mitral valve. Roles of the cleft and the accessory chordae. Chest. 1992;101: $12-5$.

5. Takenaga M, Ohno M, Hara K, Tsuneyoshi H, Takeuchi H, Kashida M, et al. Mitral regurgitation due to abnormal reinsertion of chordae tendinae (looping) of the posterior mitral leaflet: clinical and echocardiographic features. J Cardiogr. 1986; 16:919-28.

6. Parr GV, Fripp RR, Whitman V, Bharati S, Lev M. Anomalous mitral arcade: echocardiographic and angiographic recognition. Pediatr Cardiol. 1983;4: 163-5.

7. Perez JA, Herzberg AJ, Reimer KA, Bashore TM. Congenital mitral insufficiency secondary to anomalous mitral arcade in an adult. Am Heart J. 1987; 114:894-5.

8. Antonov OS, Kuznetsov VA. Echocardiographic diagnosis of anomalous chordae of the left ventricle. Kardiologiia. 1986;26:68-71.

9. Kuznetsov VA, Antonov OS, Korzhenkov AA. Supernumerary chordae of the left ventricle. Vrach Delo. 1989;4:54-5.

10. Sforza V, Toti P, Disanto A. A rare aberrant chorda tendinea in the left atrial side. Arch De Vecchi Anat Patol. 1982;65:109-12.

11. Dawson D, Mankad P, Bloomfield P, Boon NA. An unusual cause of severe mitral regurgitation: aberrantly inserted chordae tendineae. J Am Soc Echocardiogr. 2008;21:90.

12. Vlassak I, Mumtaz M, Pettersson G, Thomas JD. Accessory fibrous band causing anterior mitral valve leaflet restriction. Ann Thorac Surg. 2002;74:592-3.

\title{
Acute torsion of the left lower lobe caused by chronic traumatic hernia of the diaphragm
}

\author{
Yugo Tanaka, MD, ${ }^{\mathrm{a}}$ Wataru Nishio, MD, ${ }^{\mathrm{b}}$ Daisuke Hokka, MD, ${ }^{\mathrm{a}}$ Shiro Kawamura, MD,
}

Etsuji Shimada, $\mathrm{MD},{ }^{\mathrm{c}}$ and Shuuichi Okumura, $\mathrm{MD},{ }^{\mathrm{c}}$ Kobe, Japan

From the Department of General Thoracic Surgery ${ }^{\mathrm{a}}$ and Surgery, ${ }^{\mathrm{c}}$ National Hospital Organization Kobe Medical Center, Kobe, Japan and the Division of Thoracic Surgery, ${ }^{\mathrm{b}}$ Kobe University Graduate School of Medicine, Kobe, Japan.

Disclosures: None.

Received for publication April 16, 2008; revisions received May 14, 2008; accepted for publication May 26, 2008; available ahead of print Sept 16, 2008.

Address for reprints: Yugo Tanaka, MD, Department of General Thoracic Surgery, National Hospital Organization Kobe Medical Center, 3-1-1, Nishiochiai, Sumaku, Kobe, Japan, 654-0155 (E-mail: yugo-ta@m2.dion.ne.jp).

J Thorac Cardiovasc Surg 2010;139:e4-6

0022-5223/\$36.00

Crown Copyright (c) 2010 by The American Association for Thoracic Surgery doi:10.1016/j.jtcvs.2008.05.061
Lung lobar torsion is very rare and mostly occurs after lobectomy. We present a rare case of acute torsion of the left lower lobe caused by chronic traumatic hernia of the diaphragm that was successfully treated with resection of the left lower lobe and repair of a traumatic diaphragmatic rupture.

\section{CLINICAL SUMMARY}

A 42-year-old man was admitted to our hospital with back pain and high fever that had been increasing for a week. His medical history included only a motor vehicle accident that had occurred 22 years before, causing left diaphragmatic rupture. Repair of the diaphragmatic rupture was suggested 


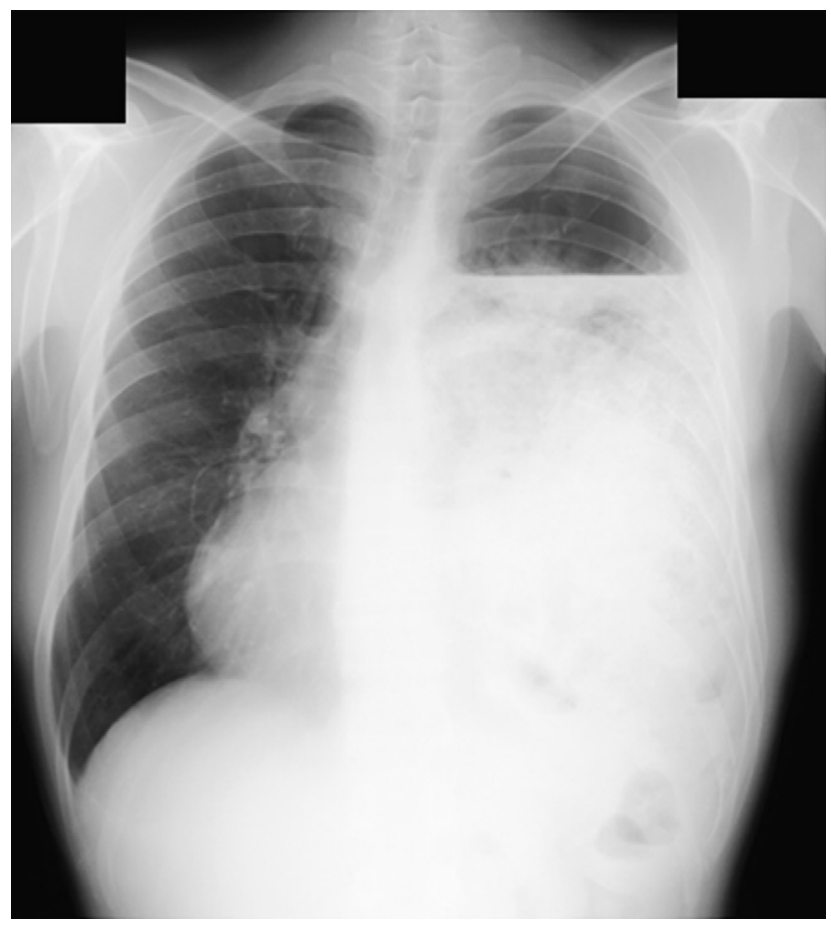

FIGURE 1. Chest radiogram obtained on admission showing a cystic lesion and opacity in the left lung field.

at the time, but he refused because of lack of symptoms. After the accident, he had no trouble with daily life for 22 years. A chest radiogram on admission demonstrated a cystic lesion and opacity in the left lung field (Figure 1). Computed tomographic (CT) analysis showed a diffuse infiltrative shadow on an air bronchogram. CT also showed displacement of the intestines within the thoracic cavity and a cystic lesion with fluid collection in the distended left lung, which caused mediastinal shift (Figure 2). Bronchoscopy revealed a near-complete occlusion of the left lower bronchus. The patient was given a diagnosis of pneumonia, and antibiotics (doripenem, $1 \mathrm{~g} / \mathrm{d}$ ) were systemically administered. However, his laboratory data did not indicate improvement, and CT scanning revealed new fluid collection in the left lung. The patient was given a diagnosis of a left lung abscess, and emergency surgery was performed through a left posterolateral thoracotomy. The maximum diameter of the diaphragmatic rupture was $10 \mathrm{~cm}$. The stomach, transverse colon, and small intestine were observed in the thoracic cavity through this rupture. The small intestine was strongly adhered to the left lower lobe and could not be detached, and therefore a part of the small intestine was resected. The congested left lower lobe was distended to twice its normal size, resulting in compression of the mediastinum and the left upper lobe, and the left lower lobe appeared to have torsion of $180^{\circ}$ around the left inferior pulmonary vein. Left lower lobectomy and repair of the diaphragmatic rupture were performed. The patient recovered and was discharged on postoperative day 32. Pathologic

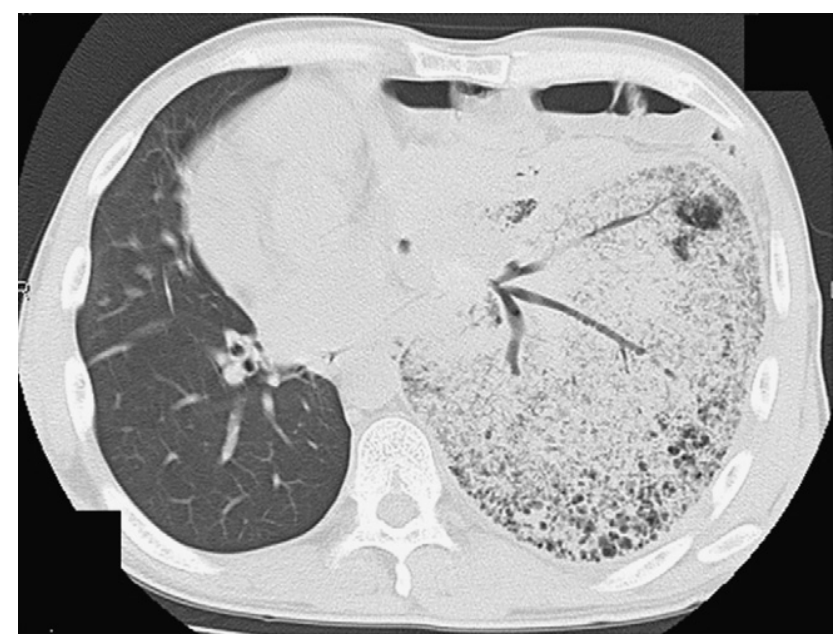

FIGURE 2. Computed tomographic scan showing displacement of the intestines within the thoracic cavity and a diffuse infiltrative shadow on an air bronchogram of the distended left lung that compressed the mediastinum.

examination revealed that the congested left lower lobe had diffuse gangrenous changes, and there was no remarkable finding in the resected small bowel.

\section{DISCUSSION}

Lung lobar torsion is a very rare disorder that has been reported to occur under 3 different circumstances as a complication of thoracic surgery, after blunt trauma, and as a spontaneous occurrence. ${ }^{1}$ Most cases of lung lobar torsion occur after thoracic surgery, ${ }^{2,3}$ and published reports have documented that the incidence of postoperative lung lobar torsion is $0.089 \%$ to $0.3 \%$. ${ }^{1}$

To our knowledge, this is the first case report of lung lobar torsion caused by traumatic diaphragmatic rupture. Additionally, in this case more than 20 years passed before the onset of lung torsion, and it is a significant event to notify. Twenty-two years later, the patient had back pain and high fever a week before hospitalization, when lung torsion seemed to have developed.

With regard to the occurrence mechanism, it was quite complicated. A common inflammatory disorder in the left thoracic cavity, such as pneumonia, might be the trigger of all the events that occurred in this patient. Congestion of the lung and edema of the adhered tissue around the dislocated left lower lobe facilitated the development of lung torsion. A distinctly lobated left lung might also affect this occurrence.

Traumatic diaphragmatic rupture occurs in $1 \%$ to $7 \%$ of patients with major blunt trauma and in $10 \%$ to $15 \%$ of patients with penetrating trauma. ${ }^{4}$ Approximately $90 \%$ of diaphragmatic ruptures occur on the left side. ${ }^{5}$ Diaphragmatic rupture can result in ileus, respiratory distress, and cardiac insufficiency, and therefore repair of the diaphragmatic rupture should be performed as soon as possible after the 
diagnosis has been confirmed. In this case not treating the traumatic diaphragmatic rupture for a long period caused a very rare complication. Arriving at the diagnosis of diaphragmatic rupture was difficult because we did not consider the possibility of diaphragmatic rupture causing lung lobar torsion. However, torsion was suggested by the opacity observed in the left lung on the chest radiogram and the nearcomplete occlusion of the bronchus revealed by means of bronchoscopy. ${ }^{1-3}$ It is important to consider that lung lobar torsion can occur as a a result of diaphragmatic rupture, and repair should be performed before lung lobar torsion occurs.

\section{References}

1. Cable DG, Deschamps C, Allen MS, Miller DL, Nichols FC, Trastek VF, et al. Lobar torsion after pulmonary resection: presentation and outcome. J Thorac Cardiovasc Surg. 2001;122:1091-3.

2. Kanaan S, Boswell WD, Hagen JA. Clinical and radiographic signs lead to early detection of lobar torsion and subsequent successful intervention. J Thorac Cardiovasc Surg. 2006;132:720-1.

3. Sticco CC, Andaz S, Fox S. Middle lobe torsion after right upper lobectomy: a report of video-assisted thoracoscopic management. $J$ Thorac Cardiovasc Surg. 2007;134:1090-1.

4. Reber PU, Schmied B, Seiler CA, Baer HU, Patel AG, Buchler MW. Missed diaphragmatic injuries and then long-term sequelae. J Trauma. 1998;44: 183-8.

5. Wiencek RG, Wilson RF, Steiger Z. Acute injuries of the diaphragm: an analysis of 165 cases. J Thorac Cardiovasc Surg. 1986;92:989-93.

\title{
Heparin-induced thrombosis without thrombocytopenia
}

\author{
Frederick A. Tibayan, MD, ${ }^{\mathrm{a}}$ Lawrence L. Leung, MD, ${ }^{\mathrm{b}, \mathrm{c}}$ Thomas A. Burdon, MD, ${ }^{\mathrm{a}, \mathrm{d}}$ and \\ James I. Fann, MD, ${ }^{\text {a,d }}$ Stanford and Palo Alto, Calif
}

Heparin-induced thrombocytopenia (HIT) is a prothrombotic complication of heparin therapy mediated by antibodies that recognize platelet factor 4/heparin complexes and cause platelet activation and thrombin generation. Early recognition of HIT and treatment with non-heparin anticoagulants are essential in reducing thrombotic events, but diagnosis of HIT in patients postcardiac surgery may be confounded by thrombocytopenia because of bleeding, infection, drugs, or intraaortic balloon pump counterpulsation. Furthermore, postoperative thrombocytosis after cardiac surgery may mask platelet consumption because of HIT. ${ }^{1}$

HIT is typically suspected in patients with thrombosis or thrombocytopenia, usually defined as a platelet count less than $100,000 / \mu \mathrm{L}$ or relative decrease of $30 \%$ to $50 \% .^{2-5}$ We present a patient in whom HIT developed without thrombocytopenia after off-pump coronary artery bypass grafting.

\section{CLINICAL SUMMARY}

A 55-year-old man with coronary artery disease, diabetes mellitus, hyperlipidemia, and hypertension presented with

From the Department of Cardiothoracic Surgery, ${ }^{\mathrm{a}}$ Department of Medicine, Division of Hematology, ${ }^{b}$ Stanford University, Stanford, Calif and Section of Hematology ${ }^{c}$ and Cardiothoracic Surgery, ${ }^{\mathrm{d}}$ VA Palo Alto HCS, Palo Alto, Calif.

Disclosures: None.

Received for publication June 4, 2008; accepted for publication July 4, 2008; available ahead of print Sept 22, 2008.

Address for reprints: James I. Fann, MD, 300 Pasteur Drive, Stanford, CA 94305-5247 (E-mail: jfann@stanford.edu).

J Thorac Cardiovasc Surg 2010;139:e6-7

0022-5223/\$36.00

Crown Copyright (C) 2010 Published by Elsevier Inc. on behalf of The American Association for Thoracic Surgery

doi:10.1016/j.jtcvs.2008.07.006 an acute coronary syndrome. Coronary angiogram demonstrated multivessel coronary artery disease. He was placed on a heparin drip. The following day, he underwent a 2-vessel off-pump coronary artery bypass, during which he received 15,000 units of unfractionated heparin intravenously. He was given no heparin postoperatively. On postoperative day 2, his platelet count decreased from 213 to $168 \mathrm{~K} / \mu \mathrm{L}$ (Figure 1). A heparin-induced antibody test was sent, the result of which was negative.

On postoperative day 12 , computed tomography of the chest, which was obtained to evaluate a fever, decrease in oxygen saturation to $93 \%$, and mild increase in heart rate, demonstrated a saddle pulmonary embolus (Figure 2). The patient was otherwise asymptomatic. Lower-extremity ultrasound showed a thrombus in the left popliteal vein. The patient was anticoagulated with intravenous argatroban after obtaining specimens for and pending results of heparin-induced antibody and heparin-induced platelet aggregation tests. The results of the heparin-induced antibody and heparin-induced platelet aggregation were positive. The transition to oral anticoagulation with warfarin was made, and the patient was discharged on postoperative day 28 . Follow-up computed tomography before discharge demonstrated significant diminution of the pulmonary embolus. He remained well at the 3-month follow-up.

\section{DISCUSSION}

HIT is a life-threatening complication in patients undergoing cardiac surgery. Early detection and anticoagulation may limit morbidity caused by HIT, but the diagnosis of HIT in patients undergoing cardiac surgery is confounded 